\title{
Role and Status of English and Other Languages in Nepal
}

Sagun Shrestha

\begin{abstract}
This paper analyses the role and status of English and other languages in Nepal as well as talks about the attitude of several agents towards English and other languages when used in the domains such as education, media and business. Nepal is a culturally and linguistically diversified country and has undergone various socio-political changes in a very short span of time primarily beginning from 1950 as of now. These changes include abolition of Panchayat, a system in which the king ruled directly led to a democratic country and end of a decade long civil war as well as abolition of monarchy which led to a country as the federal republic. These socio-political changes have made a direct significant impact on language planning and policy. The official language, Nepali and the international language, English are the dominant languages in Nepal which in many cases overshadow the promotion of other vernacular languages. As a result, a majority of people opt for these dominant languages overlooking their own indigenous linguistic affluence. In this paper, as a conclusive remark, I also argue that some plans followed by pragmatic measures are needed to uplift the status of majority of other languages in Nepal.
\end{abstract}

Keywords: English and other languages, monolingual policy, multilingualism

\section{Introduction}

Nepal, a small Himalayan country spreads across a total of 147,181 square kilometres. It lies in between the two big and economically powerful giants of Asia: China in the north and India in east, west and south. It is a landlocked country where 122 languages are spoken (Ethnologue, 2016). The data of the total number of languages varies as Central Bureau of Statistics, Nepal (2011) records 123 languages in total. All these languages have been divided broadly into 4 language families except Kusunda, which is a language isolate. The languages are Indo-European spoken by 82.10 percent, Sino Tibetan by 17.30 percent, Austro Asiatic 0.19 percent and Dravidian by 13 percent of the total population of Nepal that is, 26,494,504 (Yadav, n.d.). Nepali is the language spoken by the highest number of 11,826,953 speakers (Population Census, 2011) which falls on Indo European family, and it is followed by Maithili, 3,092,530 speakers, Bhojpuri, 1,584,958 speakers, Tharu, 1,529,875 speakers and Tamang 1,353,311 speakers which are the languages spoken by over one million people (Yadav, n.d.). The first three languages belong to Indo European family whereas the Tamang language belongs to Sino Tibetan family. Gadhawali is the least 
spoken language and it records only 38 people as its native speakers. As far as the English language is concerned, Population Census, 2011 records 2,032 speakers using English as a mother tongue in Nepal.

As regards Nepal's geo structure, it is divided into Terai: the southern belt, the Hilly region: the midland and Mountain region: the northern belt bordering China which is the least populated region of Nepal. The population is dense in southern belt as it is the plain land having a plethora of industries, and so is in the hilly region as the capital and other small valleys locate in this region. The capital city, Kathmandu has people speaking almost all the languages since many people from all parts of Nepal migrated to this city once the civil war broke out in 1995; however, Newari speakers are considered as the native people of this city. In Terai belt, Nepali, Maithili, Bhojpuri and Tharu speakers constitute the large number, and in Mountain belt, there are mostly the Nepali, Tamang and Sherpa speakers (Population Census, 2011).

Despite Nepal's relatively small geographical area with a large number of languages, the international language English is considered the dominant language in this country due to its massive spread and use in media, education, diplomacy and tourism. "The spread of English across sectors and regions is rapid and systematic... has reached the lower strata of the population in urban, as well as rural regions" (Giri, 2009, p. 93). English is the most preferred language and people working in all areas put effort to speak English creating their own context. Eagle (1999) states " one encounters street peddlers, bicycle rickshaw pullers, taxi drivers, trekking guides, porters and street children who speak surprisingly fluent English. Most of them are unschooled" (p. 308). It is valid still at this point of time. The priority has been extended from common people to the intellects now. Feeling the strength of English in Nepal, the Second National Convention of teacher of English recommended that English, being the only language of education and communication, should be given due credit in language policy documents and funds should be allocated accordingly (Yadav as cited in Eagle, 1999). In the following sections, I will describe the status and roles of English and other languages.

\section{The status of English in Nepal}

Kachru (1992) referring to the sociolinguistic profile of English draws three concentric circles: the inner circle, outer circle and the expanding circle. He states that inner circle refers to the context of core countries in which English is spoken as their first language. The USA, the UK, New Zealand, Canada and Australia fall in this circle. Similarly, outer circle comprises the linguistic situation of those countries who have institutionalized English in their regions as they have passed through the colonization e.g., India, Ghana, Bangladesh, Kenya, Pakistan, Nigeria among others. The ultimate circle i.e., expanding circle represents the large linguistic context that includes the countries who treat English as a Foreign Language (EFL) and use extensively. Nepal falls in the expanding circle of Kachru's concentric division.

In 1892, the first contact that people of Nepal, particularly the elite, made with English was through the first school that was established then to give English Education to Rana children (The Times of India, 2011) but it was not spread out as Rana regime focused to educate only Ranas. Giri (2010) mentions "English soon became the symbol of status, power and privileges, and a means to divide people into the rulers and the ruled" (p. 93) and Rana enjoyed during their time. He furthers that English only came to formal education in the beginning of twentieth century. Primarily it began flourishing after 1990 in the changed political context. The schools followed the British Education 
system that marched ahead with the English Education system of India where a goal of education was to yield the people having English in tastes, in opinions, in morals and intellects (Awasthi as cited in Giri, 2010). Then 1990 onwards, private schools start to mushroom which had a kind of brand that read 'English medium School'. In the recent years, the medium of instruction in private schools is English and following this trend, to compete with private ones, the statefunded schools have started shifting to English Medium Instruction (EMI). In this regard, referring to the entire Asian context, Philipson (1992) states "English has retained its privileged position in the education process in Asia" (p. 28), and Nepal is warmly welcoming this trend. This same tendency is massively present in media practice too. There are lots of programmes that are run only in English and a lot more are run in English and Nepali, the dominant languages in the present day socio-linguistic context. Likewise, since Nepal's economy is largely dependent upon tourism, most of the Nepalese living even in hinterlands have very basic English that serves meeting the purpose of mutual intelligibility to communicate with the foreign tourists.

Crystal (2003) claims that English has no official status in South Asian context like in Nepal; however, it is used as a medium in international communication. He further says "Increasingly it is being perceived by young South Asians as the language of cultural modernity" (p. 29) and it is true in Nepal. It is spoken by many Nepali youth taking it as a matter of pride. For them, speaking English is a prestige related new fad. In mass media, education and business too, English is given preference to other languages. Pointing out the importance of English in the country like Nepal, Phillipson (1992, p. 30) states:
The importance of English in such African and Asian Periphery-English countries is two-fold. English has a dominant role internally, occupying space that other languages could possibly fill. English is also the key external link, in politics, commerce, science, technology, military alliances, entertainment and tourism.

This is obvious that since Nepal had a monolingual language policy for quite a long time before 1990, English occupied the position of other languages and it was treated more like second language in many contexts and yes, it is a key link language in all the domains of socio-linguistic context. If so, what about other languages and how were they treated?

\section{The status of other languages}

Like English, the use of Nepali is widespread across most domains such as, education, mass media, business and arts. It is the only official language as of now. Nepal experienced the democratic reigns twice, 1950-1960 and 1990-2002. However, as regards the language policy, there was no liberal planning but rather adopted Nepali-only language policy thereby banning the indigenous languages and other than the standard variety in English (Phyak, 2013) It was a kind of biased treatment to other vernacular languages. "Moreover, languages other than Nepali were assumed to be 'barbarian', 'uncivilized' and 'worthless'" (Sachdev as cited in Phyak, 2013, p. 130).

The linguistic issues in 1990 constitution is quite vague. It mentions:

1. The Nepali language in the Devnagari script is the language of the nation of Nepal. The Nepali language shall be the official language. 
2. All the languages spoken as the mother tongue in the various parts of Nepal are the national languages of Nepal. (part 1, Article 6)

It implies that Nepali is only the nation language. It didn't clearly articulate what it means to be national languages. It seems to have played with some linguistic terms rather than giving some kind of status to the languages. The further dispute that Giri (2010) mentions is about the 1999 verdict that Supreme court gave as using the Newari (also called Nepal Bhasha) as an official language in Kathmandu Metropolitan City and Maithili, another local language in Rajbiraj and Janakpur City Councilasunconstitutional. This shows the unfair treatment made to the local/ minority languages during these time. Because of such practice, "the identity discourse" against "traditionalist discourse" (Phyak, 2013, p. 130) advocating for the recognition of minority languages was loud enough. As a result, the Interim Constitution of Nepal 2007 addressed this issue which is clearly seen in article 5, clause 3.

\section{Language of the nation:}

(1) All the languages spoken as the mother tongue in Nepal are the national languages of Nepal.

(2) The Nepali Language in Devnagari script shall be the official language.

(3) Notwithstanding anything contained in clause (2), it shall not be deemed to have hindered to use the mother language in local bodies and offices. State shall translate the languages so used to an official working language and maintain record thereon. (Part 1, Article 5)
The articles of the Interim constitution of Nepal related to language policy became liberal and opened the door for the use of minority languages in offices and similarly it also opened the possibility of Multilingual Education (MLE) which was practiced from 2007. However, the teaching learning materials and resources have not been sufficiently developed to promote MLE. As a result, this simply seems to be a sketchy provision for the local indigenous languages. It again reflects the same hierarchy that Nepali as the official language and English as the modern language enjoys as the dominant languages in Nepal.

\section{The role of English and other languages}

English being a very widely used international language in Nepal has a bigger role in education, media, business and tourism. Giri (2010) mentions that English functions as a power language working as a medium and resource for social mobility, linguistic superiority and educational and economic benefits. It has played the key instrumental role for education and further to socio-economic development. Similarly, from the list of other languages, Nepali and some other major languages have helped in business, education and arts. Nepali has played a key role performing as an official language and as a lingua franca within the nation whereas other languages have no as such bigger role than creating a kind of linguistic solidarity particularly serving for intraethnic communication, and these local languages have not been fully acknowledged yet having them used in various domains. Recently there has been an effort of the government of introducing MLE to promote local languages and it was piloted from 2007 to 2009 (Phyak, 2013). However, there have been several factors like the parents' interest to educate their 
children in English, low-possessive attitude of the community towards local languages and lack of teaching learning resources in the local languages that have significantly affected MLE in Nepal. As a result, to a large extent, Nepali as an official language and English as an international language enjoy a kind of hegemony and regularly threatening the survival of local languages. Right now as per the Ethnologue (2016), two languages namely Waling and Pahari Palpa are the extinct languages, and the other languages viz., Baram, Kusunda, Saam and Ghandruk Sign languages are in the verge of extinction. They have been listed as nearly extinct by the Ethnologue (2016). Since English and Nepali are dominantly used in education, business, mass media and tourism, the new generation don't bother of learning their mother tongues and parents don't show the interest of teaching their languages either. In the following section, I will discuss the role of English and other languages critically in education, business and mass media and tourism.

\section{Role in education}

This is the age of technological advancement and undoubtedly, English has a significant role to play. Nepal, in its own pace, is slowly walking towards such an advancement as a result, the people and academic institutions of this country have given a high priority to the English language. All the private schools are English-medium now, and even some state owned schools have already started this trend. Most of the state-owned schools' medium of instruction is in Nepali. There are only a few schools and few resources that target MLE. It seems the priority for mother tongue in education is so limited. Consequently, English and Nepali has got the bigger and significant role in education. (Phyak, 2013, p.131) states:
Due to its instrumental value, English is perceived as the most important language (even more important than Nepali) in education, mass media, and other job markets (especially due to technological requirements).

However bigger role they are having, Nepali and English should not be treated as "killer languages" (Phillipson, 1997, p. 243). Moreover, there has to be a planning of strengthening other languages by using them in several own local contexts.

\section{Role in business and mass media}

Eagle (1999) claims the language of diplomacy and international affairs in Nepal is English, and communication with other countries is done in the same language. She adds that Nepal gets a lot of foreign aids in different domains like education, communication, engineering, medicine and the list goes on and on from the foreign countries or the institutions like World Bank and United Nations, and the language used is in English. That is true whereas in business at the local level, Nepali language is used as a local link language. Similarly, in mass media too, using English seems to be a kind of fandom, and several programs are run in English and there are a plenty of programs run in Nepali. State run media run a very limited programs in local languages and privately managed media do not have it in their priority. The state owned paper entitled 'Gorkhapatra' has dedicated a page for local languages to publish their news and articles in local languages once a month recently. This seems to be a praiseworthy step to give a kind of recognition to local languages. 


\section{Role in tourism}

Tourism is considered to be a major source of income in Nepal. "Since 1950, the tourist industry has grown rapidly in Nepal, accounting for 30 percent of the total foreign exchange entering the country" (Jha as cited in Eagle 1999, p. 315). Therefore, people in almost all touristic destinations speak basic English which has a kind of mutual intelligibility. It begins from the airport and continues up to the rural hinterlands. English has played a role of subsistence in the community level. These days, even some travel agencies focus on other international languages like Chinese and Spanish too. Likewise, at the local level for local tourist, Nepali is used for the communication. There is no any noticeable role of local languages in tourism.

\section{Attitude towards English and other languages}

Phyak (2013) talks about monocentric nationalism which became dominant until 2006 and further maintains that as Nepal was dominated by monolingual policy or Nepalitization/Nepalification ideology during this time, it was an internal colonization of Nepali language overruling all other local languages which was considered as a threat to national unity and other public domains. In the same line, Eagle (1999) mentions:

The choice of Nepali as the sole national language of Nepal and the sole language to be used in the school system was, and continues to be, highly controversial. The central government rationale for this decision. was based on the fact that Nepali had been the lingua franca of the country for at least 150 years (1999, p. 288-289)
As monolingual policy was adopted, there was a massive spread of Nepali being the language of ruling class "which reinforces a stifling, oppressive and fatalistic caste system" (Eagle, 1999, p. 292). It has led to a serious repercussion. This monolingual policy happened to systematically supress marginalized local languages in which speakers of these languages lost their faith in their languages and wanted to fall in the mainstream life to get benefitted from and adopt the cultures which are not theirs (Giri, 2010). This seems to be a kind of paradigm shift which can infuse "cultural anarchism" (Giri, 2010, p. 88) any time.

Phyak (2013) mentions that even in the changing context, the policy makers' will to remain in the status quo by not recognizing the value of literacy in mother tongues seems to be a mentality of hegemony. It is of a few dominant elites in political, economic, education and linguistic power that maximizes social exclusion and inequality as the local languages are sidelined. This is their "eliteinjected backdoor language policy" (Phyak, 2013, p. 140). He says Ministry of Education has introduced a new-language-ineducation policy in which it states that local languages should be used as a medium of instruction up to grade three, but there's a lack of scholarship that can explore how this policy is implemented and supported by the agents like teachers, parents and students. Although there's a kind of ideological space for the minority languages in the changing socio-political context after 2007, the private and public schools have given a bigger room for the expansion of Nepali and English.

English and Nepali are enjoying their heydays in Nepal as of now, and other vernacular languages are struggling for their status. The communities take their languages as the commodity that has been passed from 
their elder generations rather than their linguistic affluence. Everyone seems to be joining the craze over learning and speaking English and parents don't care of transferring their local tongues to their children, rather they focus their children to be proficient in English and Nepali. Phyak (2013) mentions that there has to be a critical dialogue between agents like parents, students, teachers that can influence in policy making and implementation process.

\section{Conclusion}

It is evident that the spread of English is rapid in Nepal due to its significant role in education, diplomacy, mass media, technology and tourism. Nepalese people's attitude is shifting, preferring to speak more English compared to any other languages. Similarly, as the Nepali language has got official status, there's no any as such threat to the Nepali language but the threat is there with other vernacular languages as Ethnlogue (2016) records that 32 are in vigorous state, 54 languages are in trouble and 8 are dying out of 122 languages of Nepal. Therefore, without negating the fact that English and Nepali have bigger roles in this changing context, the government of Nepal has to start planning for standardizing some languages, probably by codifying (creating lexicography) introducing it in education at least beginning from a mono-lingual community and using it in a local media. If on one hand, the discourse on identity issue gets enlarged and on the other hand, the policy and planning of the country simply overlooks, it may bring a kind of linguistic tension which can provoke any kind of anarchism in the community in future. So the state needs to review its plan and practices in time to protect other vernacular languages without mitigating the role of official language as Nepali and International language as English. The policy in the paper may not be enough; this has to be slowly put into practice. Linguistic and cultural diversity is the affluence of Nepal and the Nepalese and it has to be preserved well.

\section{References}

Central Bureau of Statistics. (2011). National Population and Housing Census 2011 (National Report). Retrieved from http://unstats.un.org/ unsd/demographic/sources/census/ w phc/Nepal/Nepal-Census-2011Vol1.pdf

Crystal, D. (2003). English as a global language. England: Cambridge University Press.

Eagle, S. (1999). The language situation in Nepal. Journal of Multilingual and Multicultural Development, 20(4), 272-327.

Ethnologue: Languages of the world. (2016). Retrieved from https://www. ethnologue.com/country/NP

Giri, R. A. (2010). Cultural anarchism: The consequences of privileging languages in Nepal. Journal of Multilingual and Multicultural Development, 31(1), 87-100.

Interim Constitution of Nepal. (2007). Retrieved from January 24, 2016 from http://www.worldstatesmen.org/ Nepal_Interim_Constitution2007.pdf

Kachru, B.B. (1992). The other tongue. Urbana: University of Illinois Press.

Philipson, R. (1992). Linguistic imperialism. Oxford: Oxford University Press.

Phillipson, R. (1997). Realities and myths of linguistic imperialism. Journal of Multilingual and Multicultural Development, 18(3), 238-248. 
Phyak, P. (2013). Language ideologies and local languages as the medium-ofinstruction policy: A critical ethnography of a multilingual school in Nepal. Current Issues in Language Planning, 14(1), 127-143.

The Constitution of Nepal. (1990). Retrieved from January 24, 2016 from http:// www.constitutionnet.org/files / 1990_constitution_english.pdf

The times of India. (2011). Nepal's oldest school starts sexual revolution. Retrieved from http://timesofindia.indiatimes.com/ world/south-asia/Nepals-oldestschool-starts-sexual-revolution/ articleshow/9210209.cms

Yadav, Y.P. (n.d.). Academia. Language use in Nepal. 51-72. Retrieved from https:// www .academia.edu / 21009495 / LANGUAGE_USE_IN_NEPAL
Acknowledgement: I would like to sincerely acknowledge Dr. Richard Smith, who first made me explore on this topic.

The author: Sagun Shrestha is a 2016 Hornby scholar for the postgraduate course in English Language Teaching at the University of Warwick, UK. He has served as the coordinator for Access Program and teacher trainer in Nepal English Language Teachers' Association (NELTA). Equally, he has worked as an English teacher for more than seven years in Nepal. An editorin-chief of 'The GEM 2012', he has been co-editing the e-zines, 'NELTA ELT Forum' and 'The Warwick ELT' recently. 